\title{
Roles of the Cited Author in Citations of the Literature Review by EFL Postgraduates
}

\author{
Nayef Jomaa Jomaa (Corresponding author) \\ School of Languages, Civilisation and Philosophy, Universiti Utara Malaysia, UUM, Sintok 06010, Kedah, Malaysia \\ E-mail: nayef.jomaa@yahoo.com \\ Siti Jamilah Bidin \\ School of Languages, Civilisation and Philosophy, Universiti Utara Malaysia, UUM, Sintok 06010, Kedah, Malaysia \\ E-mail: siti764@uum.edu.my
}

\author{
Received: 11-08-2016 \\ Accepted: 25-10-2016 \\ Advance Access Published: November 2016 \\ Published: 10-12-2016 \\ doi:10.7575/aiac.ijalel.v.5n.7p.213 \\ URL: http://dx.doi.org/10.7575/aiac.ijalel.v.5n.7p.213
}

The study has been made possible through the postgraduate scholarship scheme (PGS) provided by Universiti Utara Malaysia (UUM).

\begin{abstract}
The study analysed the clauses of the integral citations to identify the functional roles of the cited author ${ }^{1}$ used by EFL postgraduates. The Systemic Functional Linguistics (SFL) was adopted in analysing the clauses qualitatively. A purposeful sampling was utilized in choosing the literature review of $20 \mathrm{PhD}$ theses in Information Technology and Applied Linguistics at a public Malaysian university. In terms of the interpersonal meanings, the cited author functions as a 'Subject', a 'Complement', and an 'Adjunct'. For the experiential meanings, the cited author has functions based on the processes types used in each clause, including an 'Actor' and a 'Goal' with material processes, a 'Senser' and a 'Phenomenon' with mental processes, a 'Sayer' and a 'Verbiage' with verbal processes, a 'Behaver' with behavioural processes, a 'Carrier', a ' Carrier: Possessor', an 'Attribute', a 'Token', and a 'Value' with relational processes, and an 'Agent: Attributor' with causative processes. Other functions related to the Circumstantial under the experiential meanings involved an 'Agent', a 'Location (Place)', a 'Manner: Comparison', an 'Accompaniment' and a 'Matter'. Field and tenor affected the role of the cited author; field's effect was demonstrated by using a higher number of the cited author's roles in the Applied Linguistics, whereas tenor's influence was illustrated in assigning similar roles to the cited author in the Applied Linguistics and Information Technology. These results extend the findings of previous studies, help students in using citations in academic writing, and present more outputs about citations that can be employed pedagogically.
\end{abstract}

Keywords: academic writing, Arab postgraduates, cited Author, integral citations, Systemic Functional Linguistics

\section{Introduction}

In academic writing, writers, particularly non-native speakers of English, face great challenges due to their less practice, lack of the skills (Hartley, 2008), as well as lack of clarity about the conventions of a certain genre (Murray \& Moore, 2006). Writing in hard domains like Information Technology and soft ones like Education and Applied Linguistics requires specific skills because "writing is a skill, and writing from sources is an important sub-skill for academic writers" (Pecorari, 2008, p.2). What distinguishes academic writing from other kinds of genres is the high degree of formality required in academic texts which is considered the most challenging and intimidating issue (Hyland, 2006). Hence, citation is essential in academic writing in order to present credible and reliable information that is basic for the persuation and the acceptance of the arguments (Thompson and Tribble, 2001; Charles, 2006b; Hyland, 2009a; Hewings, Lillis and Vladimirou, 2010; Gil-Salom \& Soler-Monreal, 2011; Mansourizadeh and Ahmad, 2011; Petrić \& Harwood, 2013;Yang; 2013; Samraj, 2013; Rowley-Jolivet and Carter-Thomas, 2014; Swales, 2014). Achieving academic success is also associated with the higher use of citations and varying their purposes and rhetorical functions (Petrić, 2007). However, for writers of other languages, citing in English seems to be challenging (Charles, 2006a; Polio and Shi, 2012; Rowley-Jolivet and Carter-Thomas, 2014, p.32).

The majority of studies that addressed the citations have focused on the types of the citations adopting the classification of Swales (1990) or Thompson and Tribble's (2001) taxonomy. In Hyland's (1999) findings, the description of the cited author was limited to 'Subject', 'Non-subject', and 'Noun-Phrase', as well as Swales' (2014) latest classification of the role of the cited author included inconsistency in labeling. Hence, the present study aimed to go beyond the classification of the integral and non-integral citations; the Functional Theory was adopted in order to identify the functional role of the cited author in the integral citations under the interpersonal and ideational (experiential) metafunctions, which are associated with the two register variables: Tenor and Field, respectively

${ }^{1}$ The cited author is the author whose work has been cited 


\section{Literature Review}

Factors for variations in citation practices are not known (Swales, 2014). For instance, citation practices can be influenced by the discipline (Hyland, 1999; Thompson and Tribble, 2001; Thompson, 2002; Okamura, 2008; Harwood, 2009; Hyland, 2009a; Shi, 2012; Petric' and Harwood, 2013; Hu and Wang, 2014), language (Gil-Salom and SolerMonreal, 2011; Rowley-Jolivet and Carter-Thomas, 2014; Hu and Wang, 2014), experiences of writers (Mansourizadeh and Ahmad, 2011; Samraj, 2013), and genres (Charles, 2006b; Yang, 2013; Samraj, 2013). Thus, each discipline has its own ideology and epistemology (Maroko, 2013). For example, writing $\mathrm{PhD}$ theses is varied based on the language used and the discipline to which the $\mathrm{PhD}$ thesis belongs (Irvin, 2010). On the one hand, $\mathrm{PhD}$ theses of arts are based on the strength of the arguments, revealing more personality and subjectivity. Similarly, theses of the social sciences are based on arguments supported by evidence. On the other hand, science theses are less based on arguments (Parry, 1998). These differences enforce the traditional division that puts the natural sciences and technology on one side as hard disciplines, whereas humanities are on the other side as soft ones, and social sciences are inter-mediating the two (Coffin, et al., 2003; Hyland, 2006, 2009b, p.63). Therefore, due to the differences of citation practices of each discipline, it is a 'danger' to adopt general rules related to citation practices because they cannot be 'valid in certain contexts’. (Shi, 2012, p.145).

Citations were divided by Swales (1990, 2014) into two types: the integral and the non-integral citations. The former type integrates the cited author within the structure of the clause, giving him/her the function of a subject, an agent or a part of a noun phrase (Swales, 2014). For instance, in the following citation 'Swales (1990) divided citations into two types.', the cited author 'Swales' is integrated with the clause, and functions as the subject. On the other hand, in the non-integral citation, the cited author occurs in parenthesis or represented by a number. For example, in the following citation 'Citations were divided into two types (Swales, 1990).', the cited author is not integrated with the clause; therefore, it is called a non-integral citation.

In another study, Thompson $(2001,2002)$ subcategorized the integral citation into three subcategories. For example, the subcategory Verb Controlling in 'Davis and Olson (1985) define a management information system more precisely as...", focuses on the use of the verb rather than on the role of the cited author. The other subcategory Naming is used to refer to the citation as a part of an NP, as in the example ' Typical price elasticities of demand for poultry products in Canada, Germany and the UK are shown in Harling and Thompson (1983)". The third subcategory, Non-citation, refers to the other two subcategories except that the year is not used with the cited author. However, such usages do not present a sufficient description of the citations that include more than one clause with more than one category in the same citation.

In Swales' (2014) latest classification of the role of the cited author, there is inconsistency in labelling. For example, the cited author as an 'adjunct' is classified under the functional label, whereas an 'NP' belongs to the class label. Moreover, the cited author functioning as a 'subject' can be also a part of an 'NP'. For example, the cited author in the following example 'Myers (1966) hypothesized that the freshwater fishes of the West Indies dispersed from Central America. . . . (BIO.G2.01.1)", has the role of the 'subject', and it is also a part of an 'NP' at the same time. Furthermore, the role played by the cited author as an 'adjunct' does not cover all other roles under this classification.

Consequently, the universal pedagogical approach in teaching citations has failed to present a comprehensible, sufficient view of the diversity and complexity of the citations (Hu \& Wang, 2014). Hence, Hu and Wang (2014) suggest 'Importantly, pedagogical work on linguistic resources for citation needs to be informed by a coherent functional theory of language as a semiotic tool for construing ideational, interpersonal, and textual meanings in social context (Halliday \& Martin, 1993)." Systemic Functional Linguistics is a social theory of language use, in which language is structured to make simultaneously three kinds of meanings, fusing ideational, interpersonal and textual meanings together (Halliday, 1985). Ideational (experiential) meaning is concerned with making a kind of real world through the Transitivity System; in other words, experiential meanings express the real world by means of processes, demonstrated in Figure 1:

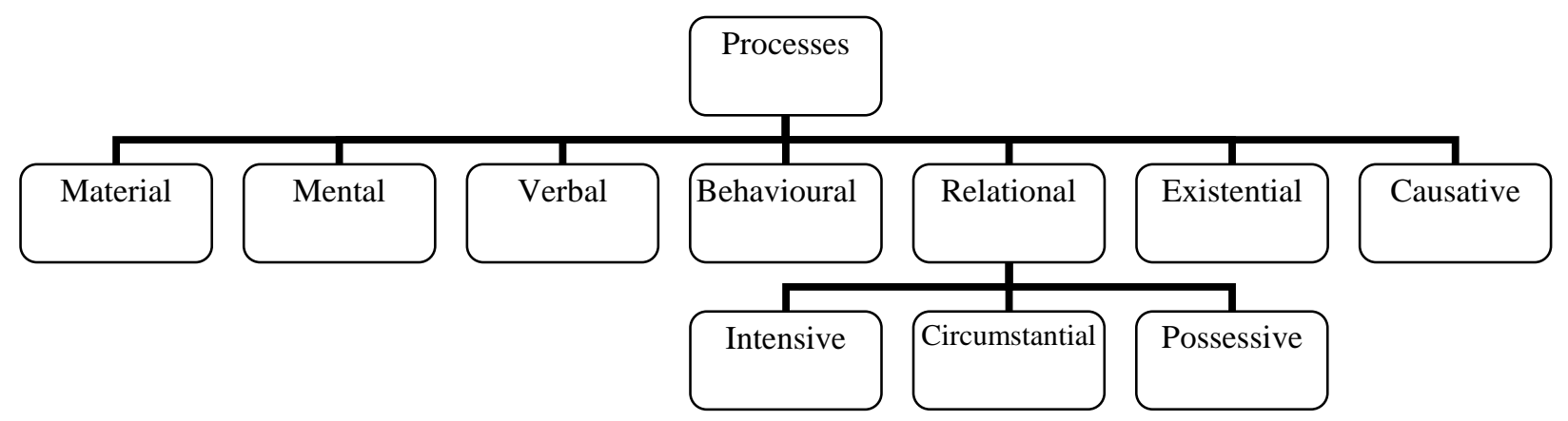

Figure 1.Types of Processes in Transitivity System (Halliday, 1985)

Examine, adopt, and use are examples of material processes. Think, feel, and believe are examples of mental processes. State, mention, argue, and suggest are examples of verbal processes. Observe, look, and notice are examples of behavioural processes. Be and become are examples of relational intensive processes. Take and last are examples of circumstantial processes. Have and possess are examples of possessive processes. Exist and be in the structure 'there 
(be)' are examples of existential processes, whereas make and encourage are examples of causative processes.

For the interpersonal meanings, they reflect the strand of meaning to express the writer's attitude and stance toward the subject matter as well as his/her role relationship with the reader. When analysing the clauses under the interpersonal meanings, constituents, such as the 'Subject', 'Predicator', 'Complement', and an 'Adjunct' are involved. The 'Subject' is the doer of the action. The 'Predicator' is the verb. The 'Complement' is the direct object, whereas the 'Adjunct' is either an adverbial or a prepositional constituent that adds unessential information to the clause. For the textual meanings, they are concerned with the way of relating and hanging what we say to what was said before and how it is related to the context around us.

Thus, due to the limited studies that adopted SFL, the aim of the present study was to identify the functional role of the cited author in the clauses of the integral citations by EFL Arab postgraduates at a public Malaysian university.

\section{Methodology}

Within the genre analysis of the textual approaches for analysing academic discourses, the Systemic Functional Linguistics was utilized as a social theory of language (Halliday and Martin, 1993).

\subsection{Procedure}

The focus was mainly on the citations in the literature review chapters of $20 \mathrm{PhD}$ theses by EFL Arab postgraduates at a public Malaysian university. Two types of analyses are possible: the macro (text) level and the micro (sentence) level (Eggins, 1994). For the present study, the micro (sentence) level of analysis was conducted taking into account only the experiential and the interpersonal meanings when analysing the clauses to identify the role of the cited author. The citations that were analysed represent the micro (sentence) level of analysis because each citation is a complete sentence, which may include either a clause simplex or a clause complex. Thus, the clause in each integral citation is the unit of analysis focusing mainly on the functional role of the cited author under these two meanings: the interpersonal and the experiential. The textual meaning was not included in analysing the roles of the cited author since identifying the interpersonal and experiential roles entails the textual ones. In the integral citations, the name of the cited author may be used or a pronoun is used to refer to him or her. For further clarification, the conceptual framework in Figure 2 that is adopted in the present study demonstrates how the integral citations are analysed through two language metafunctions of Systemic Functional Linguistics:

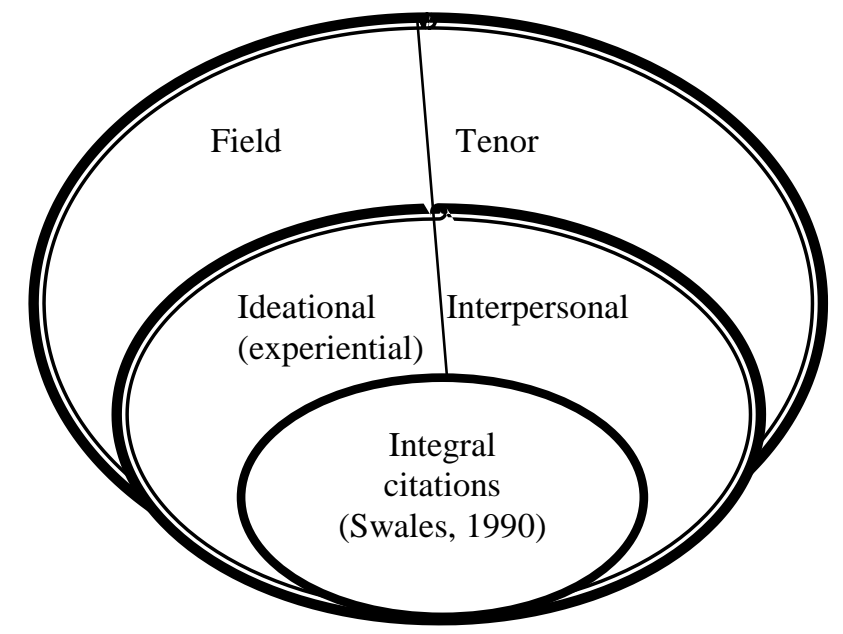

Figure 2. Conceptual Framework of the Present Study (Swales,1990; Halliday and Martin,1993)

Since the role of the cited author is limited to the integral citations in which the name of the cited author is integrated with the structure of the clause, non-integral citations are excluded. Each citation is considered as one citation regardless if it has a single citation or multiple citations. Citations that involved both the integral and the non-integral citations were also examined because the name of the cited author is integrated as a clause constituent.

The study adopted a qualitative analysis that was supported by quantifying the findings. Using numbers in qualitative studies, according to Maxwell (1992), makes a contribution to the internal generalizability of the claims of the researchers, and enables the researcher to attribute specific features to the varied perceptions, actions of groups or settings under study. Using numbers also helps identify patterns that are not apparent due to using 'unquantitized qualitative data', and present an evidence of the researcher's interpretation to counter the claim that qualitative researchers 'cherry-pick' only specific types of their data to support their interpretations (Maxwell, 2010, pp.478-480).

\subsection{Sampling}

A purposeful sampling was employed in choosing the literature review of $20 \mathrm{PhD}$ theses which are produced by EFL PhD Arab postgraduates at a public Malaysian university, and were deposited in a library of one of the public Malaysian universities. The details of these theses are presented in Table 1: 
Table 1. Data used in analysis in the present study

\begin{tabular}{|c|c|c|c|}
\hline Description of Data & Applied Linguistics & Information Technology & Total \\
\hline Number of theses (LRs) ${ }^{2}$ & 10 & 10 & 20 \\
\hline Harvard system ${ }^{3}$ & 10 & 7 & 17 \\
\hline Vancouver system ${ }^{4}$ & - & 3 & 3 \\
\hline Number of pages 5 & 736 & 656 & 1,392 \\
\hline Number of words & 185,207 & 148,383 & 333,590 \\
\hline Number of citations & 3,539 & 2,169 & 5,708 \\
\hline Number of integral citations ${ }^{6}$ & 2,446 & 1,244 & 3,690 \\
\hline
\end{tabular}

$10 \mathrm{PhD}$ theses were from Information Technology discipline (ICT or IT) which belongs to the hard domain of knowledge, where Vancouver (numbering) system was used in citations in three theses, whereas Harvard system (author, date) was used in the other $7 \mathrm{PhD}$ theses. Additionally, $10 \mathrm{PhD}$ theses that belong to the soft domain were from Applied Linguistics, where Harvard system was used in the citations in the 10 theses. 5,708 citations were extracted from the literature review chapters of $20 \mathrm{PhD}$ theses; 3,539 citations were from the Applied Linguistics theses, whereas 2,169 citations belong to the Information Technology theses. 3,690 citations were found of having the name of the cited author integrated with the structure of the clause; 2,446 integral citations are from the literature review of Applied Linguistics theses, whereas 1,244 integral citations are from the literature review chapters of Information Technology theses.

\subsection{Coding the data}

Coding was used in documenting the extracted citations for the purpose of supporting the findings with examples and abiding to the ethical issues when conducting the study. Table 2 represents the codes used under each extracted citation:

Table 2. Coding system used in documenting the data

\begin{tabular}{|ccccccc|}
\hline Participant & Discipline & Nationality & Section & Paragraph & Line & Page \\
\hline \hline P. & AL & e.g.Yemen (YE) & S. & Pr. & L. & Pg. \\
\hline
\end{tabular}

The Discipline coding also included IT to refer to Information Technology and another coding for the nationalities of the EFL Arab postgraduates; these included IR for Iraqi, SY for Syrian, JO for Jordanian, PA for Palestinian, and LI for Libyan. These $\mathrm{PhD}$ theses are written in English and a permission to use them academically was approved by the Dean of the Graduate School at the university after getting a list of EFL Arab postgraduates' names from the Graduate Studies Unit (GSU) at the university.

\section{Results}

The findings are based on the analysis of the clauses used in the integral citation by EFL Arab postgraduates in the literature review chapters of PhD theses. The Systemic Functional Linguistics was adopted in analysing the functional roles of the cited author in the clauses of the integral citations. The findings revealed that the cited author has varied functional roles. These roles exist at two levels of meanings: interpersonal and experiential.

\subsection{Cited Author: roles under the interpersonal meanings}

The cited author has different roles in the clauses under the interpersonal meanings. These roles are: a 'Subject', a 'Complement, and an 'Adjunct'.

\subsubsection{Cited Author: Subject}

In such a usage, the cited author functions as a 'Subject' of the clause in the integral citation. The 'Subject' provides the person that is responsible for the success or the failure of the proposition. When functioning as a 'Subject', the name of the cited author occurs outside the brackets in the integral citation only, as in the example (1):

(1) 'Singh [6] states that the goal of control analysis....".7 (P.16/IT/YE/S.2.4.1.4/Pr.5/L.227-229/Pg.26).

In the example (1), the cited author is 'Singh', which functions as the 'Subject' of the clause based on the interpersonal meanings.

The name of the cited author in the example (2) was replaced by a pronoun to function as a 'Subject' of the clause in the integral citation:

(2) 'He found that m-learning "has already started to play a very important role.....".

\footnotetext{
${ }^{2}$ Number of theses refers to the number of the literature review chapters of the PhD theses

${ }^{3}$ (Author, date) referencing style, e.g. (Swales, 1990)

${ }^{4}$ Number system, e.g. [1]

${ }^{5}$ Number of pages and words refers to only the literature review chapter of each $\mathrm{PhD}$ theses

${ }^{6}$ Citations with a mixed (integral and non-integral) type were considered as integral citations in the present data

7 Only the part of the citation that is involved in the analysis was mentioned, whereas the rest of the citation was omitted due to the limitations of the number of words allowed in the article.
} 
(P.14/IT/JO/S.2.4.5/Pr.5/L.304-307/Pg.38-39)

In other usages, the name of the cited author is a part of a nominal group that functions as a 'Subject' of the clause in the integral citation, as in the example (3):

(3) "'One of the limitations of Taghizadeh and Tajabadi's (2013) study is the small number of participants." (P.4/AL/YE/S.2.4.3/Pr.17/L.471-472/Pg.60)

In the example (3), the name of the cited author 'Taghizadeh and Tajabadi' is a part of the nominal group, which functions as the 'Subject' of the clause.

In some citations, particularly those extracted from the literature review chapters of IT theses, the name of the cited author is not stated explicitly; rather, it is replaced by a number, particularly in theses with a numbering (Vancouver) system used in citations. Nevertheless, the clause is analysed as having '[50]' with the function of the 'Subject' of the clause on behalf of the cited author, as in the example (4):

(4) 'Then [50] proposed an improvement, namely in the form of the Proportional Share Replication policy." (P.15/IT/PA/S.2.4.8/Pr.10/L.533-534/Pg.39)

The cited author in the abovementioned examples was used before the verb 'Predicator', following the order ( $\mathrm{S} * \mathrm{P}$ : Subject/Predicator) in active clauses. Hence, the cited author in these examples functions as the 'Subject' that is a part of the MOOD of the clause. However, when the cited author is used in passive clauses, it has another different functional role under the 'Adjunct' that is explained later under the functional role of the cited author as the 'Adjunct' (see 4.1.3 Author: Adjunct). The example (5) illustrates how the functional role of the cited author has been changed from the 'Subject' in the active clause to the 'Adjunct' when used in the passive clause:

(5) 'Distance education is defined by Greenberg et al. (1998) as „a planned teaching/learning experience.............(P.14/IT/JO/S.2.2/Pr.2/L.81-84/Pg.24)

The cited author in the example (5) is represented by 'Greenberg et al.' that is a prepositional constituent functioning as the 'Adjunct' in the passive clause of the integral citation. Hence, the roles of the cited author as the 'Subject' of the clause can be realized through the name of the cited author, the name of the cited author as a part of the nominal constituent, a pronoun or a number.

\subsubsection{Cited Author: Complement}

In this type of the functional roles, the name of the cited author, occurring alone or as a part of a nominal group, functions as the 'Complement' under the Residue part of the clause, as demonstrated in the example (6):

(6)"This study adopted Bhatia's (2004) multi-dimentional and multi-perspective framework for critical genre analysis." (P.2/AL/JO/S.2.5/Pr.1/L.1342-1344/Pg.78)

In the example (6), the name of the cited author 'Bhatia', which is a part of a nominal group, functions as the 'Complement' of the clause. The functional role of the cited author as the 'Complement' is used in active clauses; however, when the clause is turned into passive, the 'Complement' function is changed into the 'Subject', whereas the 'Subject' is turned into an 'Adjunct' which is discussed in the subsection (4.1.3) below. The example (7) demonstrates the conversion of the 'Subject' into an 'Adjunct' and the conversion of the 'Complement' into a 'Subject' in the example (8) when converting the active clause into a passive one:

(7) 'This term was coined by Vinay and Darbelnet (1995) to define '. (P.11/AL/LI/S.2.5.1.9/Pr.1/L.12391240/Pg.68)

(8) 'Bhatia's (2004) CGA approach was used in a number of recent studies...."(Bonini, 2010; Ching, 2011). (P.2/AL/JO/S.2.2.4/Pr.7/L.612-614/Pg.45)

Thus, the functional roles of the cited author as the 'Complement' can be realized through the name of the cited author or through a nominal constituent, where the name of the cited author forms a part of it.

\subsubsection{Cited Author: Adjunct}

The cited author functions as the 'Adjunct', which is a constituent of the clause under the RESIDUE part of the clause. This 'Adjunct' adds additional information that is not essential to the clause. Unlike the 'Subject' and the 'Complement' constituents, the adjuncts are not nominal; rather, the adjuncts are either adverbial or prepositional constituents, as in the examples (9) and (10):

(9) 'This point was emphasized by Swales (1990), who stated that.....". (P.2/AL/JO/S.2.4.2/Pr.7/L.12321234/Pg.74)

(10) "As has been demonstrated in [128], personal judgments.....". (P.16/IT/YE/S.2.5.4/Pr.2/L.564-566/Pg.45)

In the examples (9) and (10), the cited author functions as the 'Adjunct'. In the example (9), the name of the cited author 'Swales' is stated explicitly in the literature review chapter of a $\mathrm{PhD}$ thesis in Applied Linguistics discipline that used Harvard System (author, date referencing style), whereas in the example (10), the name of the cited author is not stated explicitly; rather, it was replaced by a number in theses using the Numbering (Vancouver) System. Nevertheless, the prepositional constituent represented by 'in [128]' still has the functional role of the 'Adjunct'.

As a result, the cited author has the functional roles of a 'Subject', a 'Complement', and an 'Adjunct' in the clauses of the integral citations under the interpersonal meanings, as summarized in the Table 3: 
Table 3. Roles of the cited author under the interpersonal meanings

\begin{tabular}{llllll}
\hline Functional roles of the cited author & \multicolumn{2}{c}{ Applied Linguistics } & \multicolumn{2}{c}{ Information Technology } & Total \\
\cline { 2 - 5 } & Frequency & Percentage & Frequency & Percentage & \\
Author: Subject & 1,925 & 67.59 & 923 & 32.40 & 2,848 \\
Author: Adjunct & 601 & 73.47 & 217 & 26.52 & 818 \\
Author: Complement & 140 & 66.66 & 70 & 33.33 & 210 \\
\hline
\end{tabular}

The findings in Table 3 show that EFL Arab postgraduates of AL discipline depended heavily on integrating the name of the cited author with the citations through the roles of the 'Subject', the 'Adjunct', and the 'Complement', whereas IT EFL Arab postgraduates depended less on integrating the name of the cited author with the citations. This shows the disciplinary influence on using citations that is represented by the Field (Applied Linguistics) as a register variable that can affect the use of language within the social context. This also reveals the effect of the domain on the use of the citations. In soft domains like the Applied Linguistics, the cited author has a prominent role; therefore, EFL Arab postgraduates integrated the name of the cited author with the structure of the clauses in the citations. On the other hand, in hard domains like the Information Technology, the focus is on the procedures and findings rather than on the cited author; therefore, the role of the cited is less emphasized, resulting in less integral citations. The density of the citations in the Applied Linguistics also affected the high percentage of using the 'Subject', the 'Adjunct', and the 'Complement' in the literature review of Applied Linguistics PhD theses. Thus, the disciplinary influence has an effect on increasing the density of the citations and the integral citations. In spite of their different domains, The Tenor (EFL Arab postgraduates) also affected the use of the cited author in the literature review of AL and IT by having the cited author with the highest percentage in the function of the 'Subject', followed by the 'Adjunct', whereas the 'Complement' occupied the lowest percentage.

\subsection{Cited Author: Roles under the experiential meanings}

Roles of the cited author under the experiential meanings involved two parts; one part of the roles is associated with the types of the processes used in the clauses of the integral citations, whereas the other part of the roles is represented by the Circumstantials that are prepositional constituents.

\subsubsection{Cited author: roles associated with processes}

Analysing the clauses of the integral citations resulted in several roles of the cited author under the experiential meanings that are directly associated with the processes types (verbs), represented by material, mental, verbal, behavioural, relational, and causative ones. These roles included 'Actor, Goal, Senser, Phenomenon Sayer, Verbiage, Behaver, Carrier, Attribute, Token, Value, Carrier: Possessor, and Agent: Attributor'.

The following subsections clarify each functional role of the cited author based on each process used in each clause of the integral citations in the literature review chapters of the PhD theses by EFL Arab postgraduates in AL and IT disciplines.

\subsubsection{Cited Author: Actor}

The cited author functions as an 'Actor' based on the processes types, such as examined, carried out, and investigated. These are material processes of DOING, representing concrete and real tangible actions, as in the example (11):

(11) "Varttala used Salager-Meyer's taxonomic model (i.e. five pre-established items.") (P.4/AL/YE/S.2.4.1/Pr.2/L.216-217/Pg.48)

In the example (11), 'used' is the material process of actions that involved actors called participants. These participants are realised by nominal groups. In the example (11), there are two participants; one of these participants is the cited author 'Varttala' functioning as the 'Actor'. Thus, the cited author functioning as an 'Actor' is the constituent of the clause who performs the action.

The cited author functioning as the 'Actor' can be in either active or passive clauses. In the active clause, it is conflated with the function of the 'Subject' under the interpersonal meanings; the roles of the 'Actor' and the 'Subject' are mapped onto the same constituent. However, in the passive, the 'Actor' at the experiential meaning is not the 'Subject' at the interpersonal meaning; they are not mapped onto the same constituent, as in the example (12):

(12) "The acceptance process model was first introduced by Rogers (1962), based on...." (P.14/IT/JO/S.2.5.1/Pr.1/L.607-609/Pg.61)

\subsubsection{Cited Author: Goal}

The cited author functions as a 'Goal' with material processes. This 'Goal' is the participant at whom the process is directed. In other words, this participant is the Direct Object in the traditional grammar, and it maps onto the 'Complement' participant in the Mood analysis of the interpersonal meanings, as in the example (13):

(13) 'Most researchers have adopted Salager-Meyer's (1994) approach in dealing with hedges and boosters in different contexts." (P.4/AL/YE/S.2.4.1/Pr.1/L.211-213/Pg.48) 
The cited author 'Salager-Meyer's', which is a part of a nominal group, has the function of the 'Goal' under the experiential meaning based on the material process 'adopted'. The same constituent has the function of a 'Complement' under the interpersonal meanings. Thus, the 'Complement' at the interpersonal meaning and the 'Goal' at the experiential meanings are mapped onto the same constituent when they are used in active clauses.

\subsubsection{Cited Author: Senser}

The cited author functions as a 'Senser' participant depending on the mental process types, such as think, believe, and feel that are used in the clause of the citation. These processes may vary including cognition verbs such as thinking, knowing, and understanding, affective verbs, such as liking and fearing, and perception verbs, such as seeing and hearing. With any of these subdivisions of the mental processes, the cited author functions as a 'Senser'. This 'Senser' participant feels, thinks or perceives the phenomenon, as in the examples (14) and (15):

(14) "'In other words, Kaplan believes that as children acquire their native language,..." (P.4/AL/YE/S.2.6/Pr.1/L.600-603/Pg.66-67)

(15) "Mehlinger $(1995$, p. 3) feels that there is no need to be careful...." (P.6/AL/IR/S.2.9.1/Pr.5/L.919920/Pg.68)

In the examples (14) and (15), the cited authors 'Kaplan' and 'Mehlinger' play the functional role of the 'Senser' under the experiential meanings based on the mental processes 'believes' and 'feels' which were used in the clauses of the citations, respectively.

\subsubsection{Cited Author: Phenomenon}

The other participant that is involved with the clauses of mental processes is called the 'Phenomenon'; the participant is a nominal group that can be represented by an abstract noun.

(16) 'Generally, the present research considers Faerch and Kasper's (1983a) taxonomy as a better classification of the OCSs." (P.19/AL/YE/S.2.5.4.3/Pr.6/L.440-441/Pg.25)

In the example (16), the name of the cited author is a part of a nominal constituent, which functions as the 'Phenomenon' because the mental process 'considers' was used. The role of the cited author as a 'Phenomenon' at the experiential meanings and the role of the cited author as a 'Complement' at the interpersonal meanings are conflated onto the same constituent in active clauses.

\subsubsection{Cited Author: Sayer}

Clauses with verbal processes, such as point out, suggest, indicate, argue and say contain three participants: a Sayer, a Receiver, and a Verbiage. The cited author in such clauses functions as the 'Sayer', who is a conscious participant, responsible for the verbal processes, and capable of putting out a signal, as in the examples (17) and (18):

(17) "Hinkel and Fotos (2002) argue that there is no single best approach in grammar .." (P.6/AL/IR/S.2.1/Pr.1/L.6-7/Pg.22)

(18) Meanwhile, [39] proposed a replica placement scheme that tries to overcome the ...............(P.15/IT/PA/S.2.4.8/Pr.4/L.486-487/Pg.37)

The cited authors 'Hinkel and Fotos' in the example (17) and '[39]' replacing the name of the cited author in the example (18) play the functional role of the 'Sayer' under the experiential meanings based on the verbal processes 'argue' and 'proposed', used respectively. Similarly, the role of the cited author as a 'Senser' and the role of the cited author as a 'Subject' are also mapped onto the same constituent in the active clauses.

\subsubsection{Cited Author: Verbiage}

The cited author also functions as the 'Verbiage' participant when used in clauses with verbal processes. The 'Verbiage' is a nominalized statement of the verbal process which represents or expresses a kind of a verbal behaviour, as in the example (19):

(19) 'This finding agrees with that of Ling and Baron's (2007), who reported that $60 \%$ of the text messages...". (P.10/AL/JO/S.2.4.2.2/Pr.5/L.1630-1631/Pg.103)

In the example (19), the name of the cited author is a part of a nominal constituent that functions as the 'Verbiage' in the clause with the verbal process 'agrees'. The role of the cited author as a 'Verbiage' at the experiential meanings is conflated with the role of the cited author as a 'Complement' at the interpersonal meanings in active clauses.

\subsubsection{Cited Author: Behaver}

The cited author functions as a 'Behaver' when used in clauses with behavioural processes, which are of physiological and psychological behaviour that intermediate between the material and the mental processes. The 'Behaver', represented by the cited author, is a conscious being, as demonstrated in the example (20):

(20) 'In order to answer this question, Baron (1998) looked at the social dynamics,email format, grammar and style of email..." (P2/AL/JO/S.2.4.2/Pr.2/L.1171-1172/Pg.71)

In the example (20), the behavioural processes 'looked' was used. Therefore, the cited author 'Baron' plays the functional role of the 'Behaver'. Similarly, the 'Behaver' is mapped onto the same constituent of the 'Subject' constituent when used in the active clause. 


\subsubsection{Cited Author: Carrier}

In active clauses that include relational intensive processes, the relationship between the two terms (Carrier) and (Attribute) is one of the sameness. In such clauses, the cited author plays the functional role of the 'Carrier' that is realized as a nominal group or a pronoun, as demonstrated in the example (21):

(21) 'Halliday's (1985) approach is functional grammar.....". (P.2/AL/JO/S.2.2.1/Pr.1/L.176-178/Pg.26)

Similarly, the functional role of the cited author as a 'Carrier' conflates with the functional role of the cited author as a 'Subject' in active clauses.

\subsubsection{Cited Author: Attribute}

In active clauses that include relational intensive processes, the second constituent that follows the process is called the 'Attribute' that is realized as a nominal group. The cited author in such clauses plays the functional role of the 'Attribute', as demonstrated in the example (22):

(22) 'It is Chomsky's (1965, p.3) idealized way in approaching language that aims to specify the universal principles...”. (P.1/AL/IR/S.2.3.1/Pr.2/L.62/64/Pg.33)

In the example (22), the relational intensive process ' $i s$ ' was used in the clause of the citation, and the name of the cited author 'Chomsky' which is a part of the nominal constituent plays the functional role of the 'Attribute'. Similar to the functional role of the cited author as a 'Goal', a 'Verbiage', and a 'Phenomenon', the functional role of the cited author as an 'Attribute' is conflated with the functional role of the cited author as a 'Complement' in active clauses.

\subsubsection{Cited Author: Carrier: Possessor}

In clauses with the relational possessive processes, the relationship between the two terms is one of the ownership; one entity possesses the other. In such clauses, the process reflects the ownership relationship, where the cited author is a nominal group that plays the functional role of the 'Possessor', as demonstrated in the example (23):

(23) "'Romaine (1994) for instance has one such definition..." (P.1/AL/IR/S.2.4/Pr.1/L.278-280/Pg.43)

In the example (23), the citation includes a clause with the relational possessive process 'has', in which the cited author 'Romaine' functions as the 'Carrier: Possessor', which conflates with the functional role of the cited author as a 'Subject' in active clauses.

\subsubsection{Cited Author: Token}

In clauses that include relational intensive identifying processes, the cited author functions as the 'Token', as in the example (24):

(24) 'Dewey (1933) and Schon $(1983,1987)$ are two of the most cited contributors to foundational concepts of reflective practice" (York-Barr et al., 2006). (P.5/AL/YE/S.2.2/Pr.3/L.29-30/Pg.32)

In the example (24), the citation included the clause with the identifying intensive process 'are', in which the cited author functions as the 'Token', which is conflated with the functional role of the cited author as a 'Subject' in active clauses. The difference between the functional role of the author as a 'Token' and a 'Carrier' is that the relational intensive process with the 'Carrier' is used in clauses that are irreversible; passive cannot be formed. On the other hand, relational intensive process with the 'Token' is used in clauses that are reversible; passive can be formed.

\subsubsection{Cited Author: Value}

In clauses with the relational intensive processes that are reversible, the cited author can be a nominal constituent that functions as the 'Value', as in the example (25):

(25) "Several researchers have delved into the notion of writing stages and among them are Emig (1977); Perl (1980); and Sommers (1980)". (P.3/AL/JO/S.2.2/Pr.2/L.61-62/Pg.23).

The cited authors 'Emig, Perl, and Sommers' in the example (25) are a nominal constituent used in the clause with the relational intensive process 'are'. In such a usage, the cited author functions as a 'Value' that is conflated with the functional role of the cited author as a 'Complement' in active clauses.

\subsubsection{Author: Agent 'Attributor'}

In the example (26) below, the cited author 'Gardner and Lambert' is a part of the nominal constituent which functions as an 'Agent: Attributor' because it is followed by the causative process 'led'.

(26) "Gardner's and Lambert's (1972) research led them to propose two types of motivation in language learning...." (P.19/AL/YE/S.2.11.2/Pr.1/L.1003-1007/Pg.60)

Table 4 below summarizes the functional roles of the cited author that are associated with the processes types in the clauses of the integral citations under the experiential meanings: 


\begin{tabular}{|c|c|c|c|c|c|}
\hline \multirow[t]{2}{*}{ Roles of the cited author } & \multicolumn{2}{|c|}{ Applied Linguistics } & \multicolumn{2}{|c|}{ Information Technology } & \multirow[t]{2}{*}{ Total } \\
\hline & Frequency & Percentage & Frequency & Percentage & \\
\hline Author: Sayer & 1160 & 73.97 & 408 & 26.2 & 1568 \\
\hline Author: Actor & 589 & 54.28 & 496 & 45.71 & 1085 \\
\hline Author: Senser & 219 & 78.49 & 60 & 21.50 & 279 \\
\hline Author: Goal & 114 & 67.05 & 56 & 32.94 & 170 \\
\hline Author: Carrier & 68 & 79.07 & 18 & 20.93 & 86 \\
\hline Author: Attribute & 28 & 68.29 & 13 & 31.70 & 41 \\
\hline Author: Carrier (Possessor) & 24 & 77.41 & 7 & 22.58 & 31 \\
\hline Author: Verbiage & 18 & 81.81 & 4 & 18.18 & 22 \\
\hline Author: Behaver & 16 & 80 & 4 & 20 & 20 \\
\hline Author: Phenomenon & 10 & 90.90 & 1 & 9.10 & 11 \\
\hline Author: Value & 5 & 55.55 & 4 & 44.44 & 9 \\
\hline Author: Token & 4 & 100 & - & - & 4 \\
\hline Author: Agent 'Attributor' & 1 & 100 & - & - & 1 \\
\hline
\end{tabular}

The role of the cited author as a 'Sayer' dominated the integral citations in the literature review chapters of Applied Linguistics, whereas the role of the cited author as an 'Actor' dominated the integral citations in the literature review chapters of Information Technology. These findings demonstrate evidently that field represented by Applied Linguistics and Information Technology is a register variable that affects the use of the integral citations. Soft domains like Applied Linguistics are based on arguments; therefore, EFL Arab postgraduates emphasized the role of the cited author by integrating him/her with the structure of the clause in the citations, giving him/her the role of the 'Sayer' that is used with verbal processes. On the other hand, hard domains like Information Technology are based on facts rather than arguments; therefore, the name of the cited author was emphasized through using the material processes, giving him/her the role of the 'Actor'. This finding is another evidence of the distinction between the hard domains and the soft ones, in which Field plays the role of the disciplinary factor in affecting the use of the integral citations and the high percentage of certain roles of the cited author.

\subsubsection{Cited author: roles as circumstantial}

The role of the cited author as a 'Circumstantial' under the experiential meanings adds more meanings to the clause of the integral citations, represented by Location (Place), Agent, Manner (Comparison), Matter, Accompaniment, and others.

\subsubsection{Cited Author: Location (Place)}

In this type of the Circumstantial roles, the cited author is represented by a possessive adjective that is a part of a prepositional constituent. In such citations, the cited author functions as the place of the information from which a piece of information was cited by the citing writer, as in the example (27):

(27) "'In her research, she used different types of authentic materials..." (P.6/AL/IR/S.2.8.1/Pr.13/L.472473/Pg.44)

(28) "According to Meyer (2001), context is arguably an under-theorized area within the CDA approach." (P.12/AL/IR/S.2.18/Pr.3/L.1509-1510/Pg.93).

In the example (27) the name of the cited author is represented by the possessive adjective in the prepositional constituent 'in her research' to refer to the place of the information. In the example (28), the name of the cited author 'Meyer' is a part of the prepositional constituent which functions as the Location (Place) of the cited information. The functional role of the cited author as a 'Location (Place)' under the experiential meanings is conflated with the functional role of the cited author as the 'Adjunct' under the interpersonal meanings.

\subsubsection{Cited Author: Agent}

The cited author functions as the 'Agent' in passive clauses, preceded mainly by the preposition 'by' as in the example (29):

(29) 'The TCP NewReno variant was proposed in 1995-1996 by Floyd et al. [37].." (P.7/IT/SY/S.2.1.4.3/Pr.4/L.217-220/Pg.28-29)

In the example (29), the cited author 'Floyd et al' is a part of the prepositional constituent preceded by the preposition 'by' and functions as an 'Agent'. The role of the cited author as an 'Agent' is conflated with the functional role of the 
cited author as an 'Adjunct' under the interpersonal meanings. In other usages of the cited author as an 'Agent', the name of the cited author is not mentioned explicitly; rather, it is represented by the preposition 'by' to refer to the cited author as an Agent and expressed by numbers in brackets used in theses employing Numbering System in citations, as in the example (30):

(30) "Meanwhile, an optimal replication strategy (DORS) has been proposed by [111]..." (P.15/IT/PA/S.2.4.5/Pr.10/L.322-324/Pg.28)

In the example (30), the name of the cited author is not stated explicitly; nevertheless, it is still considered as an integral citation, where the cited author has the role of the 'Agent' in the clause.

\subsubsection{Cited Author: Manner (Comparison)}

The cited author plays the role of the 'Manner (Comparison)' when used to compare the cited author with other authors or studies. In such a usage, the cited author is a part of a prepositional constituent that refers to either his/her study, methodology, or findings to compare them with other authors' studies or findings, as in the example (31):

(31) 'In line with Hillock's study, Anderson, Saden and Hunter (2001) examined the writing of 30 undergraduate psychology students." (P.4/AL/YE/S.2.7/Pr.4/L.722-723/Pg.72)

\subsubsection{Cited Author: Matter}

In such a usage, the cited author 'Rummens' is a part of a prepositional constituent that plays the role of the 'Matter', as demonstrated in the example (32):

(32) ''For Rummens (1993), it is the distinctive character possessed by an individual..' (P.12/AL/IR/S.2.9/Pr.1/L.512-514/Pg.45)

\subsubsection{Cited Author: Accompaniment}

The name of the cited author can be a part of a prepositional constituent that functions as an 'Accompaniment', as in the example (33):

(33) "The shift started with Labove's (1966, 1972a; Trudgill, 1974) view of style variation as different levels...."(P.1/AL/IR/S.2.3.2/Pr.6/L.142-146/Pg.37).

In the example (33) the name of the cited author 'Labove' is a part of a prepositional constituent that functions as the 'Accompaniment'. This role is conflated with the role of the cited author as an 'Adjunct' under the interpersonal meanings in active clauses.

In summary, when the cited author is used as a prepositional constituent or a part of it, he/she several functional roles under the experiential meanings to add more information that is not essential to the clause. These roles of the cited author are represented mainly by Location (Place), Agent, Matter, Manner (Comparison), Accompaniment, and others, which are demonstrated in Table 5:

Table 5. Roles of the cited author as circumstantial under the experiential meanings

\begin{tabular}{llllll}
\hline \multirow{2}{*}{ Cited author as circumstantial } & \multicolumn{2}{c}{ Applied Linguistics } & \multicolumn{2}{c}{ Information Technology } & Total \\
\cline { 2 - 5 } & Frequency & Percentage & Frequency & Percentage & \\
\hline Author: Location (Place) & 346 & 71.48 & 138 & 28.51 & 484 \\
\hline Author: Agent & 177 & 73.14 & 65 & 26.85 & 242 \\
\hline Author: Matter & 39 & 86.66 & 6 & 13.33 & 45 \\
\hline Author: Manner (Comparison) & 36 & 80 & 9 & 20 & 45 \\
\hline Author: Accompaniment & 4 & 80 & 1 & 20 & 5 \\
\hline Author: others & 21 & 80 & 14 & 40 & 35 \\
\hline
\end{tabular}

In spite of their different domains, the cited author functioning as a 'Location (Place)' dominated the integral citations in the literature review chapters of Applied Linguistics and Information Technology theses, followed by the role of the cited author as an 'Agent'. On the other hand, the role of the cited author as a 'Matter', a 'Manner (Comparison)', and an 'Accompaniment', occupied a lower occurrence in the integral citations of the literature review chapters of Applied Linguistics and Information Technology PhD theses. This shows the effect of the Tenor represented by EFL Arab postgraduates who have relatively similar educational, cultural, and social backgrounds. Thus, Tenor affects using the cited author with similar roles in two different fields. On the other hand, the highest percentage of using the cited author with several roles in the integral citations of the literature review chapters of Applied Linguistics demonstrates the disciplinary influence on the role of the cited author. This latter finding illustrates the effect of the Field on using the role of the cited author in the literature review chapters of Applied Linguistics PhD theses. Thus, the Tenor represented by EFL Arab postgraduates and the Field represented by Applied Linguistics and Information Technology are register variables that affect the use of the cited author in the integral citations of the literature review chapters of Applied Linguistics and Information Technology $\mathrm{PhD}$ theses.

Based on identifying the roles of the cited author at the interpersonal ${ }^{8}$ and experiential ${ }^{9}$ meanings in the integral

8 Arrows represent the functional roles of the cited author under the interpersonal meanings.

9 Squares represent the functional roles of the cited author under the experiential meanings. 
citations of the literature review chapters of Applied Linguistics and Information Technology by EFL Arab postgraduates, Figure 3 summarizes these roles:

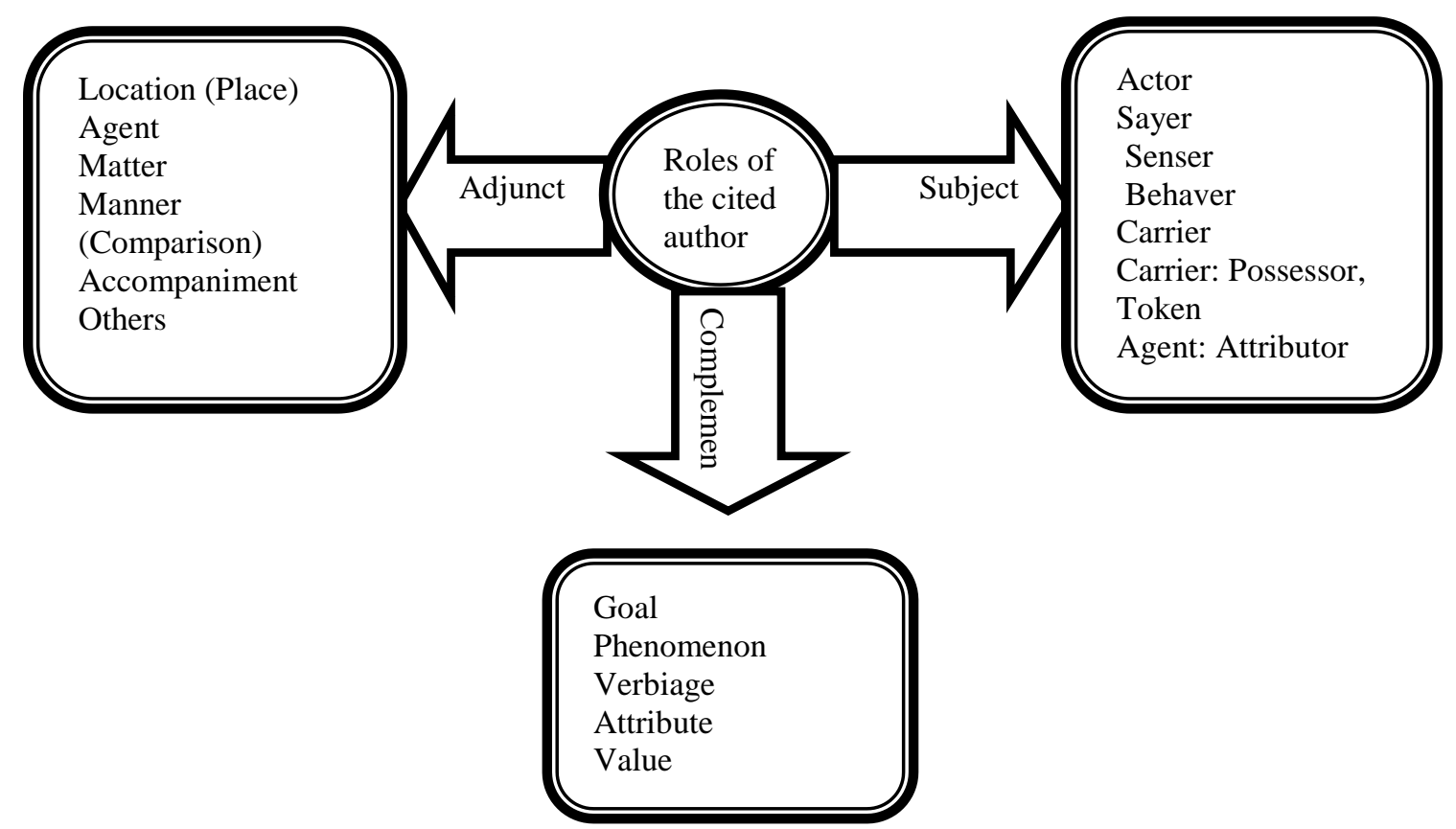

Figure 3. Conflation of the Cited Author's Role at Interpersonal and Experiential Meanings

The roles of the cited author at the interpersonal meanings are conflated with the roles of the cited author at the experiential meanings when used in the active clauses of the integral citations, except for the role of the cited author as an 'Agent' which must be in the passive clause.

\section{Discussion, conclusions, and future research}

The present study aimed at identifying the roles of the cited author in the integral citations of the literature review of $\mathrm{PhD}$ theses by EFL Arab postgraduates in two disciplines: Information Technology and Applied Linguistics through the Systemic Functional Linguistics Approach. The clause in each integral citation was analysed with respect to two types of meanings: the interpersonal and the experiential meanings. The findings of the study presented a systematic description of the roles of the cited author in the clauses of the integral citations. Therefore, a re-classification of the cited author's role is derived from the results of the study and presented in Figure 3 (p.11)

Under the interpersonal meanings, the 'Subject' role dominated the literature review chapters of AL and IT PhD theses, followed by the 'Adjunct' role, whereas the 'Complement' role was the least used one. These findings evidence the effect of the Tenor (EFL Arab postgraduates) in assigning similar roles to the cited author. The Field also has an effect on using these roles with a higher number (Subject:1925, Adjunct: 601, Complement: 140) in the literature review chapters of Applied Linguistics theses compared with a lower number (Subject: 923, Adjunct: 217, Complement: 70) in the literature review chapters of Information Technology.

The two roles of the cited author, 'Subject' and 'Adjunct', are similar to Swales' (2014) findings. However, the findings of the present study are more comprehensive because Swales'(2014) findings seem to be inconsistent; his classification of the cited author's role included class labelling (Author in NP) and other Functional labeling (Subject, Agent, Adjunct). Using Swales' (2014) classification may lead to a kind of misclassifying the role of the cited author because the cited author in the 'Subject' position can be also an 'NP' at the same time. However, through adopting the SFL in analysing the functional role of the cited author in the present study, using 'Adjunct' to classify the role of the cited author at the interpersonal meanings also included the role of the cited author as the 'Agent' at the experiential meanings. This classification seems to contrast with the findings of Swales' (2014) who addressed the two roles of the cited author that are 'Agent' and 'Adjunct' separately. Another missing role of the cited author in Swales' (2014) findings is 'Complement'; this role was not mentioned in his study, but in the present study, it was found that the cited author has the role of the 'Complement' at the interpersonal meanings.

The dominance of the 'Sayer' role $(n=1160)$ of the cited author in the integral citations of the literature review chapters of $\mathrm{AL}$ on the one hand and the dominance of the role of the cited author as an 'Actor' $(\mathrm{n}=496)$ in the integral citations of the literature review chapters of IT theses on the other hand can be attributed to the effect of the Field as a disciplinary influence on the use of the cited author in the integral citations. The disciplinary influence represented by the Field was also clear in using the roles of the cited author with a higher percentage in the integral citations of the literature review chapters of Applied Linguistics theses, compared with Information Technology. These findings imply that EFL Arab postgraduates in the soft domain put more emphasis on what the cited author says, whereas, in the hard domain, the emphasis is on what the cited author does. These findings re-enforce the distinction between Applied Linguistics as a soft domain and the Information Technology as a hard one. 
The variety of the cited author's roles that are determined by the processes types, such as 'Actor, Goal, Sayer, Verbiage, Senser, Phenomenon, Behaver, Carrier, Carrier: Possessor, Attribute, Token, Value, and Agent: Attributor', which were not included in Swales' (2014) findings, reveal that several processes are used in the citations; they are not limited only to the three types of reporting verbs, such as research acts, cognition acts, and discourse acts which were explored by several studies (Thompson and Ye,1991; Thomas and Hawes, 1994, Hyland, 1999; Yang, 2013). Additionally, the two classifications of the cited author as an 'Agent' and an 'Adjunct', which were classified separately by Swales (2014), are classified in the present study under the 'Adjunct' role at the interpersonal meanings and the experiential ones. Under the experiential meanings, the cited author plays several roles represented by the 'Agent', the 'Location: (Place)', the 'Manner (Comparison)', the 'Accompaniment' and the 'Matter', which are conflated with the role of the cited author as an 'Adjunct'

Based on Hu and Wang's (2014) suggestion, 'Importantly, pedagogical work on linguistic resources for citation needs to be informed by a coherent functional theory of language as a semiotic tool for construing ideational, interpersonal, and textual meanings in social context (Halliday \& Martin, 1993)", the present work was initiated adopting Halliday's (1985) Functional Theory in identifying the role of the cited author in the integral citations. The findings of the present study clarified the probability of applying Halliday's (1985) Functional Theory on analysing the citations types; instead of limiting the description into only integral and non-integral citations, the SFL extended the analysis and presented more comprehensive details about the roles of the cited author in the clauses of the integral citations. A modified proposed taxonomy of the roles of the cited author was presented in Figure 3 (P. 11).

The findings also demonstrated the diversity of the processes 'verbs' used in the citations based on the roles of the cited author associated with these processes; therefore, there is a need to study the usage of such processes in the citations in the different genres by Native speakers and ESL/EFL speakers because the performance of students in social science as another domain intermediating the hard and the soft domain might be different, and also the performance of students in other genres, such as academic articles and dissertations might be also different. Studying the citations can be achieved accurately and appropriately when the three register variables: Field, Tenor, and Mode are considered due to their effect on the use of the language. This was demonstrated through showing the ethnolinguistic and the disciplinary influences on the use of the citations (Hu and Wang, 2014). The findings are limited to the role of the cited author in the integral citations of the literature review of two disciplines: Applied Linguistics and Information Technology by EFL Arab postgraduates at one of the public universities in Malaysia. Nevertheless, the findings are useful in academic writing for students who pursue their postgraduate studies. The findings are also useful for those who are interested in preparing pedagogical materials for postgraduate students to enhance their academic writing skills.

\section{Acknowledgement}

I would like to thank the two anonymous reviewers and the 20 Arab postgraduates whose $\mathrm{PhD}$ theses were analysed after getting their personal data from the Graduate Studies Unit (GSU) at the university. Also, I would like to thank the Dean of AHSGS for granting us a permission to use the theses for academic purposes.

\section{References}

Charles, M. (2006a). Phraseological patterns in reporting clauses used in citation: A corpus-based study of theses in two disciplines. English for Specific Purposes. (25), 310-331.

Charles, M. (2006b). The Construction of Stance in Reporting Clauses: A Cross-disciplinary Study of Theses. Applied Linguistics. 27(3), 492-518.

Coffin, C., Curry, M. J., Goodman, S., Hewings, A., Lillis, Th.M., \& Swann, J. (2003). Teaching Academic Writing. USA and Canada: Routledge.

Eggins, S. (1994). An Introduction to Systemic Functional Linguistics. UK: Printer Publishers Ltd.

Gil-Salom, L. \& Soler-Monreal, C. (2011). A cross-language study on citation practice in PhD theses. International Journal of English Studies. 11(2), 53-75.

Halliday, M.A.K (1985). An Introduction to Functional Grammar. UK: Edward Arnold.

Halliday, M. A. K., \& Martin, J. R. (1993). Writing science: Literacy and discursive power. London: The Falmer Press.

Hartley, J. (2008). Academic Writing and Publishing: A Practical Handbook. New York: Routledge Taylor \& Francis Group.

Harwood, N. (2009). An interview-based study of the functions of citations in academic writing across two disciplines. Journal of Pragmatics. 41(3), 497-518.

Hewings, A., Lillis, T., \& Vladimirou, D. (2010). Who's citing whose writings ? A corpus based study of citations as interpersonal resource in English medium national and English medium international journals. Journal of English for Academic Purposes. 9(2), 102-115.

Hu, G., \& Wang, G. (2014). Disciplinary and ethnolinguistic influences on citation in research articles. Journal of English for Academic Purposes. 14, 14-28. 
Hyland, K. (1999). Academic Attribution: Citation and the Construction of Disciplinary Knowledge. Journal of Applied Linguistics. 20(3), 341-367.

Hyland, K. (2006). English for Academic Purposes: an advanced resource book. London: Routledge.

Hyland, K. (2009a). Writing in the disciplines: Research evidence for specificity. Taiwan International ESP Journal. $1(1), 5-22$.

Hyland, K. (2009b). Academic Discourse: English in a Global Context. London and New York: Continuum International Publishing Group.

Irvin, L. L. (2010). What Is “Academic ” Writing? Writing Spaces: Readings on Writing. Vol. (1). Parlor Press.

Mansourizadeh, K., \& Ahmad, U. K. (2011). Citation practices among non-native expert and novice scientific writers. Journal of English for Academic Purposes. 10(3), 152-161.

Maroko, G. M. (2013). Learning about author positioning in written academic discourse. Argentinian Journal of Applied Linguistics. 1(2), 47-60.

Maxwell, J. (1992). Understanding and validity in qualitative research. Harvard educational review, 62(3), 279-301.

Maxwell, J.A. (2010). Using Numbers in Qualitative Research. Qualitative Inquiry. Vol. 16(6), pp. 474-482.

Murray, R., \& Moore, S. (2006). Handbook of Academic Writing: A Fresh Approach. Buckingham, GBR: McGraw-Hill Education. Retrieved from http://www.ebrary.com.

Okamura, A. (2008). Citation Forms in Scientific Texts: Similarities and Differences in L1 and L2 Professional Writing. Nordic Journal of English Studies. 7(3), 61-81.

Parry, S. (1998). Disciplinary differences in doctoral theses. Higher Education. 36, 273-99

Pecorari, D. (2008). Academic writing and plagiarism: A linguistic analysis. London: Continuum.

Petrić, B. (2007). Rhetorical functions of citations in high- and low-rated master's theses. Journal of English for Academic Purposes. 6(3), 238-253.

Petrić, B., \& Harwood, N. (2013). Task requirements, task representation, and self-reported citation functions : An exploratory study of a successful L2 student's writing. Journal of English for Academic Purposes. 12, 110-124.

Polio, Ch. \& Shi, L. (2012). Perceptions and beliefs about textual appropriation and source use in second language writing. Editorial/Journal of Second Language Writing. 21, 95-101.

Rowley-jolivet, E., \& Carter-thomas, S. (2014). Citation Practices of Expert French Writers of English: Issues of Attribution and Stance. A.Lyda and K. Warchal (eds.), Occupying Niches: Interculturality, Cross-culturality and Aculturality in Academic Research. Second Language Learning and Teaching. Switzerland: Springer International Publishing.

Samraj, B. (2013). Form and function of citations in discussion sections of master's theses and research articles. Journal of English for Academic Purposes. 12(4), 299-310.

Shi, L. (2012). Rewriting and paraphrasing source texts in second language writing. Journal of Second Language Writing. 21(2), 134-148.

Swales, J. M. (1990). Genre Analysis. Cambridge: Cambridge University Press.

Swales, J. M. (2014). Variation in Citational Practice in a Corpus of Student Biology Papers: From Parenthetical Plonking to Intertextual Storytelling. Written Communication. 31(1), 118-141.

Thomas, S., \& Hawes, T. P. (1994). Reporting verbs in medical journal articles. English for Specific Purposes. 13(2), 129-148.

Thompson, G. \& Ye, Y. (1991). Evaluation in the Reporting Verbs Used in Academic Papers. Applied Linguistics, 12(4), 365-382.

Thompson, P. (2001). A pedagogically-motivated corpus-based examination of PhD theses: macrostructure, citation practices and use of modal verbs. Unpublished thesis submitted for the degree of PhD to School of Linguistics and Applied Language Studies, The University of Reading, UK.

Thompson, P. (2002). Manifesting intertextuality in the PhD theses. Revista Canaria De Estudios Ingleses. 44, 97-114.

Thompson, P., \& Tribble, C. (2001). Looking at citations: Using corpora in English for Academic Purposes. Language Learning and Technology. 5(3), 91-105.

Yang, L. (2013). Evaluative Functions of Reporting Evidentials in English Research Articles of Applied Linguistics. Open Journal of Modern Linguistics. 3(2), 119-126. 